\title{
Unexpected reactivities in chain shuttling copolymerizations
}

Philippe ZINCK Z $^{1,2,3,4}$

1Univ Lille Nord de France, F-5900 Lille, France

2 ENSCL, UCCS, CCM, F-59652 Villeneuve d'Ascq, France

3 USTL, UCCS, CCM, F-59655 Villeneuve d'Ascq, France

4 CNRS, UMR8181, F-59652 Villeneuve d'Ascq, France

\begin{abstract}
Chain shuttling copolymerization (CSP) is a modern polymerization technique that allows in a one-step procedure the access to multiblock microstructures of statistical copolymer blocks of different composition, providing notably new thermoplastic elastomers. The process involves the shuttle of a growing copolymeric chain between two catalysts showing different reactivity ratio vs. the comonomers. The complexity of the active species formed in the presence of two catalysts and a chain transfer agent can give rise to unexpected reactivities. They are presented and discussed in this contribution, including their possible origin when provided and the consequences regarding the design of catalytic systems for CSP.
\end{abstract}




\section{Introduction}

The discovery of Ziegler Natta catalysis has led to a tremendous development of polyolefins and synthetic polydienes in the last 50 years. The advent of homogeneous catalysis has led to new concepts ${ }^{1-3}$ for the design of the microstructure and architecture of these polymers. Among them, significant interest has risen on chain shuttling copolymerization (CSP) since its discovery in $2006 .^{3}$ The process based on coordinative chain transfer polymerization $\left(\mathrm{CCTP}^{4-5}\right)$ involves a shuttle of growing copolymeric chains via a chain transfer agent between two catalysts exhibiting different reactivity ratio towards the two monomers. This leads, under favorable conditions, to unique materials exhibiting a multiblock microstructure of statistical copolymeric blocks of different composition.

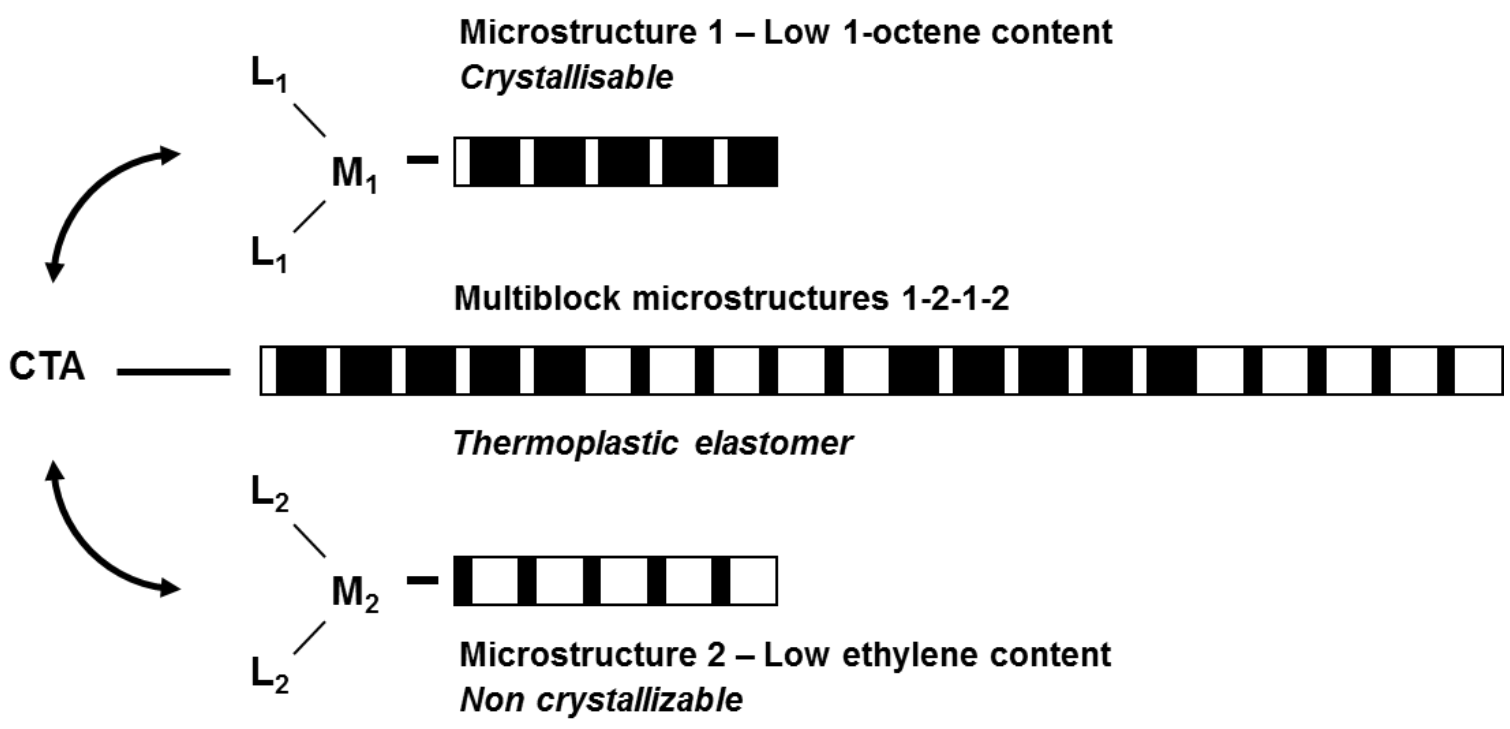

Scheme 1. Ethylene/1-octene chain shuttling copolymerization. ${ }^{3} \mathrm{M}_{\mathrm{i}}$ represent transition metals allowing propagation, $\mathrm{L}_{\mathrm{i}}$ ligands and CTA the chain transfer or chain shuttling agent. 
The studies reported in this field until now were devoted to the search for and development of new catalytic combinations, ${ }^{6-14}$ to modeling studies on the reaction kinetics and microstructure formation ${ }^{15-20}$ and to the study of the properties of the resulting materials. ${ }^{21-23}$ Several highlight articles were also proposed to the community. ${ }^{24-28}$

Although highly promising, a spectacular development of the field is probably hampered by the difficulty encountered in finding a good match between catalysts and chain shuttling agents. For instance, more than 1600 polymerization experiments were realized by high throughput screening before finding an appropriate catalytic combination and optimized conditions. $^{3}$ If some trends have been provided for finding a good match between a polymerization catalyst and a chain transfer agent, ${ }^{29-32}$ much less is known about more specific factors enabling chain shuttling copolymerization. This is probably to ascribe to an even more complex nature of the active species and the interactions occurring in the presence of two catalysts. This can lead in some cases to substantial deviations from the behavior than can be expected considering the two catalysts separately and to unexpected reactivities.

The objective of this contribution is to highlight these unusual effects by providing a report of the systems where they were observed and when possible an explanation of their origin. We hope that this discussion will help scientists interested in the quest for new catalytic systems and comonomers combinations for CSP. 

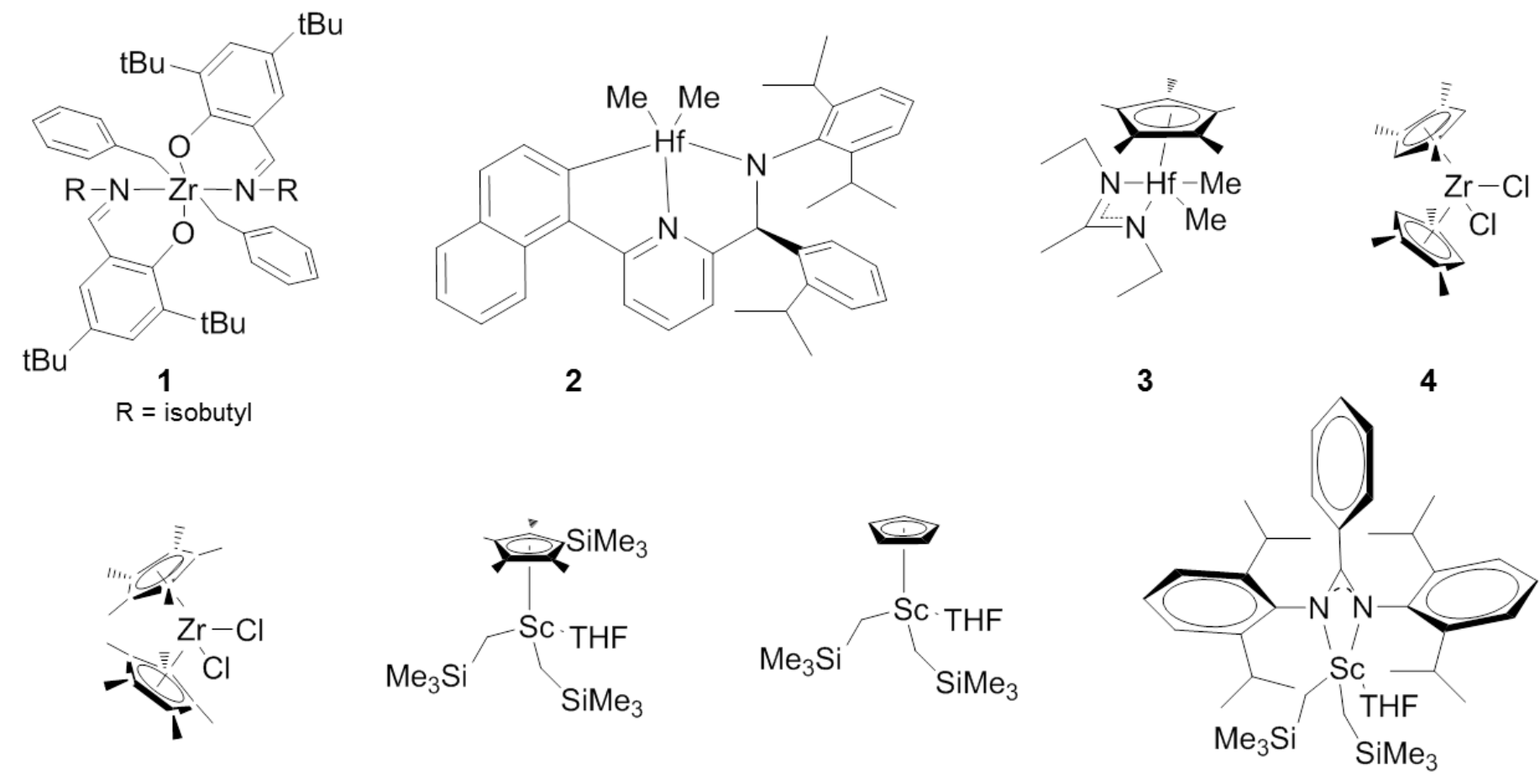

5
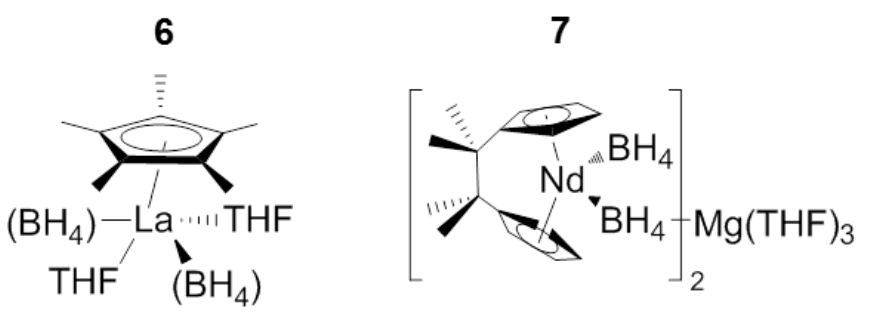

9

10

Scheme 2. Precatalysts used for chain shuttling copolymerization 


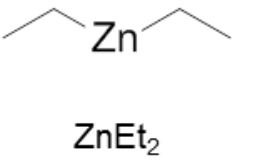

$\mathrm{ZnEt}_{2}$

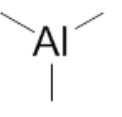

$\mathrm{AlMe}_{3}$

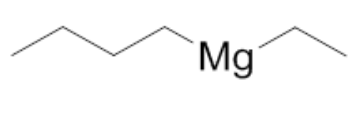

Mgn BuEt $^{\mathrm{n}}$

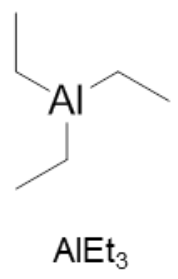

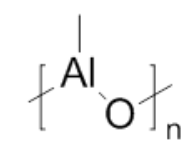

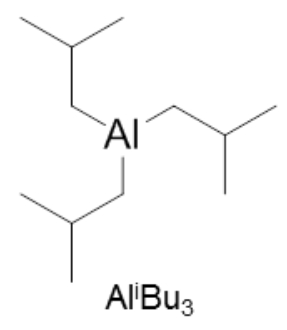

Scheme 3. Chain shuttling agents 


\section{Experimental observations of deviations from average behavior in CSP.}

Chain shuttling copolymerizations were realized so far starting from ethylene / 1-alkene as well as styrene / conjugated diene comonomers combinations. Two catalytic systems comprising diethylzinc as the chain shuttling agent were reported considering the former comonomers: (i) a bis(phenoxyimine) $\mathrm{Zr} \mathbf{1}$ / pyridylamide-Hf 2 association and (ii) a $\mathrm{Hf}$ based precatalyst 3 in combination with two different co-catalysts, a borate $\left[\mathrm{PhNHMe}_{2}\right]\left[\mathrm{B}\left(\mathrm{C}_{6} \mathrm{~F}_{5}\right)_{4}\right]$ and a borane $\mathrm{B}\left(\mathrm{C}_{6} \mathrm{~F}_{5}\right)_{3}$. If both systems leads to a behavior in CSP that can be predicted from that of the catalysts taken separately, deviations from the expected average behavior were reported in early studies $^{6}$ using the zirconocenes $\mathbf{4}$ and $\mathbf{5}$ combined to methylaluminoxane (MAO). The activity of the ethylene / 1-hexene copolymerization mediated by $\mathrm{Cp}_{2}{ }_{2} \mathrm{ZrCl}_{2}(5-1$ low 1-hexene incorporation, $\mathrm{Cp}^{*}=$ pentamethylcyclopentadienyl) is $c a .6$ times lower than that mediated by $\left(1,2,4-\mathrm{Me}_{3} \mathrm{Cp}\right)_{2} \mathrm{ZrCl}_{2}(4-$ high 1-hexene incorporation $-\mathrm{Cp}=$ cyclopentadienyl). This lower activity is explained by the accumulation of $\mathrm{Me}_{2} \mathrm{Al}$-Polymer moieties in the reactor that coordinate on the catalyst, leading to its deactivation. This lower activity is explained by the accumulation of $\mathrm{Me}_{2} \mathrm{Al}$-Polymer moieties in the reactor leading to a deactivation of the catalyst. When both catalysts are mixed together, the $\mathrm{Me}_{2} \mathrm{Al}$-Polymer moieties do not accumulate as they are removed via chain transfer to 4 . The deactivation of $\mathrm{Cp}^{*}{ }_{2} \mathrm{ZrCl}_{2} 5$ is thus significantly reduced in the dual catalytic system, leading to an enhancement in activity. This results in a copolymer with a 1-hexene incorporation $c a$. $30 \%$ lower than the average determined considered the 6 -fold higher activity of $\mathbf{4} v s .5$.

The scandium half-sandwiches based catalytic systems developed for isoprene-styrene $\mathrm{CSP}^{12}$ provides another example. Indeed, if the $\left(\mathrm{C}_{5} \mathrm{Me}_{4} \mathrm{SiMe}_{3}\right) \mathrm{Sc}\left(\mathrm{CH}_{2} \mathrm{SiMe}_{3}\right)_{2}(\mathrm{THF})$ precatalyst $(6-\mathrm{THF}=$ tetrahydrofuran $)$ combined to 1 equiv. of $\left[\mathrm{Ph}_{3} \mathrm{C}\right]\left[\mathrm{B}\left(\mathrm{C}_{6} \mathrm{~F}_{5}\right)_{4}\right]$ leads to the statistical

copolymerization of isoprene and styrene, ${ }^{33}$ its combination to $\mathbf{7}$ or $\mathbf{8}$ and $\mathrm{Al}^{\mathrm{i}} \mathrm{Bu}_{3}$ as chain 
shuttling agent for the CSP of the same comonomers leads to a multiblock microstructure of polyisoprene and polystyrene homopolymers. ${ }^{12}$ In other words, there is a critical change of the copolymerization reactivity ratio of the comonomers as compared to the behavior of the single catalysts. Similar but less impressive changes in reactivity ratio were also observed in the course of the isoprene-styrene CSP mediated by $\mathrm{Cp} * \mathrm{La}\left(\mathrm{BH}_{4}\right)_{2}(\mathrm{THF})_{2}(\mathbf{9}-$ low styrene incorporation) / $\left[\left(\mathrm{C}_{5} \mathrm{H}_{4} \mathrm{CMe}\right)_{2} \mathrm{Nd}\left(\mathrm{BH}_{4}\right)_{2}\right]_{2} \mathrm{Mg}(\mathrm{THF})_{3} \quad(\mathbf{1 0} \quad-$ high styrene incorporation $)$ associated to butylethylmagnesium. $^{14}$ The resulting multiblock microstructure of amorphous statistical copolymer was composed of soft and hard blocks, with a glass transition temperature of $-15^{\circ} \mathrm{C}$ for the former and $40^{\circ} \mathrm{C}$ for the latter. The individual catalysts taken separately leads to statistical copolymers exhibiting glass transition temperatures around $-50^{\circ} \mathrm{C}$ for $\mathbf{9}$ and $+2^{\circ} \mathrm{C}$ for $\mathbf{1 0}$ starting from the same feed. This implies that the incorporation of styrene is significantly higher both in the hard and in the soft blocks under CSP conditions. Modelling studies have led to unexpected and sometimes surprising trends, and may bring some highlights toward reactivity changes in CSP.

\section{Theoretical modeling of CSP}

Modeling studies reported so far were devoted to the analysis of copolymer composition, ${ }^{15-16}$ molecular weight distribution, ${ }^{16}$ length of the blocks, ${ }^{17}$ distribution of the number of blocks per chain ${ }^{18}$ and to more fine microstructure analysis and its evolution during the polymerization. ${ }^{19-20}$ It has notably been shown that the Mayo-Lewis equation ${ }^{34}$ may no longer be able to describe the composition of the copolymers formed instantaneously by each catalysts in CSP systems operating in a continuous stirring tank reactor (CSTR). ${ }^{15}$ This may arise when the chain transfer rate is substantially higher than the propagation rate, and may not be the case when a single catalyst is used in the presence of a chain transfer agent. As a consequence, the 
composition of the blocks in a multiblock microstructure resulting from CSP may differ from those of the statistical copolymers obtained using the catalysts separately. From this finding, and considering the aforementioned similar experimental results obtained under batch conditions, it can be concluded that it is difficult to predict / foresee the microstructure and resulting properties of a multiblock copolymer made by CSP from the composition of the blocks formed by the two catalysts separately.

The influence of the relative amount of catalysts in the reactive medium shows also some particular effects. ${ }^{16}$ Considering the system developed by Dow, the Hf based catalyst 2 inserts more 1 -octene in the copolymer than 1. From modeling studies, ${ }^{16}$ the increase of the ratio of 2 in the feed leads to an increase of the overall octene content, but to a decrease of the octene content in the soft block. This is due to a decrease of the octene concentration in the reactor due to a higher consummation in the presence of more 2 . The weight fraction of soft blocks does in turn increase. The influence of the catalyst concentration on the composition of the blocks can thus be counter-intuitive, as also observed experimentally. ${ }^{14}$ Finally, even if not predicted theoretically, changes in apparent copolymerization reactivity ratio are also observed for single catalyst / chain transfer agent combinations, as discussed in the next section.

\section{Unexpected reactivities observed in coordinative chain transfer copolymerizations}

\section{(CCTcoP)}

Changes in reactivity ratio upon introducing aluminum alkyls chain transfer agents in the course of the statistical copolymerization of ethylene and norbornene mediated by the $\mathrm{Zr}$ based

catalyst 11 combined to MAO were reported. ${ }^{35}$ Significant entries are reported in Table 1. Adding 200 equiv. $\mathrm{AlR}_{3}(\mathrm{R}=\mathrm{Me}, \mathrm{Et})$ to $\mathbf{1 1} / \mathrm{MAO}$ leads to an important increase of norbornene in the copolymer, which reduces upon increasing quantitites (400 and 600 eq.). Using 12 instead of 
11, the addition of $\mathrm{AlR}_{3}$ as chain transfer agent did not induce substantial changes of the composition. Rare earth borohydrides associated to magnesium dialkyls were also widely used in CCTP, ${ }^{36-41}$ and notably neodymium precatalysts for isoprene-styrene CCTcoP. Representative examples are given in Table 1. It can be seen that in the presence of 1 equiv. dialkylmagnesium, the more the bulkiness of the ligand, the highest the reactivity ratio of styrene in the course of the statistical copolymerization. When the reaction is conducted in the presence of excess chain transfer agent in CCTP conditions, substantial changes of the reactivity ratio are observed. For instance, the amount of styrene inserted in the copolymer using $\mathbf{1 3}$ and $\mathbf{1 4}$ associated to 10 equiv. chain transfer agent is higher by a factor close to 3 to that observed in the presence of 1 equiv. magnesium dialkyl. This CCTP induced changes in reactivity ratio becomes less important as the bulkiness of the ligand increases (see 15), with no changes observed using the ansaneodymocene 10. Steric hindrance as well as chain growth on the magnesium atom have been advanced to explain these effects. It should finally be noted that (i) several studies dealing with CCTcoP did not report significant changes on the copolymerization reactivity ratio, ${ }^{5}$ and (ii) theoretical modeling in a CSTR ${ }^{15}$ does not predict such changes in the case of a single catalyst / chain transfer agent mediated statistical copolymerization (CCTcoP). 


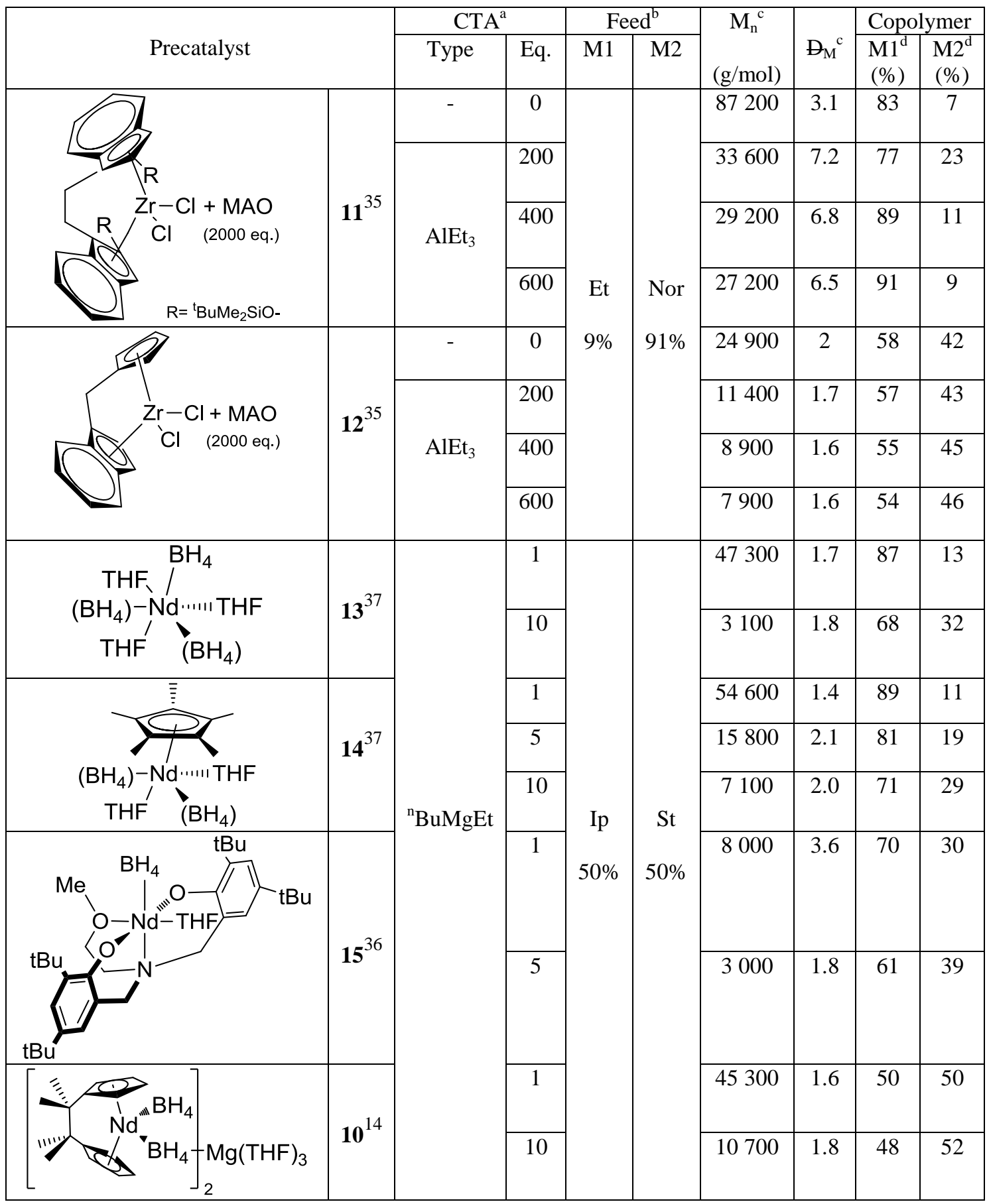

Table 1. Zirconocenes and neodymium borohydrides based catalytic systems reported for CCTcoP. ${ }^{a}$ CTA is the chain transfer agent, eq. $=$ equivalent per $\mathrm{Zr}$ or $\mathrm{Nd} ;{ }^{\mathrm{b}} \mathrm{Et}=$ ethylene, Nor $=$ norbornene, Ip = isoprene; $\mathrm{St}=$ styrene; ${ }^{\mathrm{c}}$ determined by size exclusion chromatography; ${ }^{\mathrm{d}}$ determined by NMR spectroscopy 


\section{Conclusion}

Unexpected reactivities can be observed in the course of chain shuttling copolymerizations. Substantial increase in the activity of the polymerization was observed and attributed to the scavenging of deactivating metal-polymer moieties via transmetallation between the two catalysts. Copolymerization reactivity ratio in chain shuttling copolymerization can also differ from those observed considering the catalysts individually. An important consequence is that the microstructure and thus the resulting properties of a multiblock copolymer made by CSP can not necessarily be predicted from the composition of the statistical copolymers formed by the two catalysts separately. In addition to experimental evidences of this phenomenon, theoretical modeling of CSP in a CSTR predicts such deviations when the transfer rate becomes higher than the propagation rate. Finally, changes in reactivity ratio can also be observed in the course of a statistical copolymerization conducted in the presence of a single catalyst and a chain transfer. These latter are not predicted by theoretical modeling in a CSTR, and steric effects and growth of the polymer on the chain transfer agent have been proposed to explain their origin. The unusual reactivities observed in chain transfer copolymerizations may finally also find their origin in a complex nature of the active species in multicomponent catalytic systems. The application of theoretical chemistry approaches such as DFT may certainly bring an additional view angle beneficial for the further development of the field. 


\section{References}

1 G. W. Coates and R. M. Waymouth, Science, 1995, 267, 217-219.

2Z. Guan, P. M. Cotts, E. F. McCord and S. J. McLain, Science, 1999, 283, 2059-2062.

3D. J. Arriola, Science, 2006, 312, 714-719.

4R. Kempe, Chem. - Eur. J., 2007, 13, 2764-2773.

5 A. Valente, A. Mortreux, M. Visseaux and P. Zinck, Chem. Rev., 2013, 113, 3836-3857.

6I. Bruaseth and E. Rytter, Macromolecules, 2003, 36, 3026-3034.

7F. Alfano, H. W. Boone, V. Busico, R. Cipullo and J. C. Stevens, Macromolecules, 2007, 40, $7736-7738$.

8A. Tynys, J. L. Eilertsen, J. V. Seppälä and E. Rytter, J. Polym. Sci. Part Polym. Chem., 2007, 45, 1364-1376.

9A. Xiao, L. Wang, Q. Liu, H. Yu, J. Wang, J. Huo, Q. Tan, J. Ding, W. Ding and A. M. Amin, Macromolecules, 2009, 42, 1834-1837.

10 R. L. Kuhlman and J. Klosin, Macromolecules, 2010, 43, 7903-7904.

11 J. Wei, W. Zhang, R. Wickham and L. R. Sita, Angew. Chem. Int. Ed., 2010, 49, 91409144.

12 L. Pan, K. Zhang, M. Nishiura and Z. Hou, Angew. Chem. Int. Ed., 2011, 50, 1201212015.

13 C. Descour, T. J. J. Sciarone, D. Cavallo, T. Macko, M. Kelchtermans, I. Korobkov and R. Duchateau, Polym. Chem., 2013, 4, 4718.

14 A. Valente, G. Stoclet, F. Bonnet, A. Mortreux, M. Visseaux and P. Zinck, Angew. Chem. Int. Ed., 2014, 53, 4638-4641.

15 M. Zhang, E. M. Carnahan, T. W. Karjala and P. Jain, Macromolecules, 2009, 42, 80138016. 
16 M. Zhang, T. W. Karjala and P. Jain, Ind. Eng. Chem. Res., 2010, 49, 8135-8146.

17 M. Zhang, T. W. Karjala, P. Jain and C. Villa, Macromolecules, 2013, 46, 4847-4853.

18 S. Anantawaraskul, P. Somnukguande and J. B. P. Soares, Macromol. Symp., 2012, 312, $167-173$.

19 Y. Mohammadi, M. Ahmadi, M. R. Saeb, M. M. Khorasani, P. Yang and F. J. Stadler, Macromolecules, 2014, 47, 4778-4789.

20 M. Ahmadi and A. Nasresfahani, Macromol. Theory Simul., 2015, n/a-n/a.

21 H. P. Wang, D. U. Khariwala, W. Cheung, S. P. Chum, A. Hiltner and E. Baer, Macromolecules, 2007, 40, 2852-2862.

22 D. U. Khariwala, A. Taha, S. P. Chum, A. Hiltner and E. Baer, Polymer, 2008, 49, 13651375.

23 S. Li, R. A. Register, J. D. Weinhold and B. G. Landes, Macromolecules, 2012, 45, 57735781.

24 V. C. Gibson, Science, 2006, 312, 703-704.

25 V. Busico, Macromol. Chem. Phys., 2007, 208, 26-29.

26 M. Zintl and B. Rieger, Angew. Chem. Int. Ed., 2007, 46, 333-335.

27 P. D. Hustad, Science, 2009, 325, 704-707.

28 P. Zinck, Polym. Int., 2012, 61, 2-5.

29 G. J. P. Britovsek, S. A. Cohen, V. C. Gibson and M. van Meurs, J. Am. Chem. Soc., 2004, 126, 10701-10712.

30 G. J. Britovsek, S. A. Cohen, V. C. Gibson, P. J. Maddox and M. van Meurs, Angew. Chem. Int. Ed., 2002, 41, 489-491.

31 P. Zinck, A. Valente, F. Bonnet, A. Violante, A. Mortreux, M. Visseaux, S. Ilinca, R. Duchateau and P. Roussel, J. Polym. Sci. Part Polym. Chem., 2010, 48, 802-814. 
32 R. J. Hue, M. P. Cibuzar and I. A. Tonks, ACS Catal., 2014, 4, 4223-4231.

33 H. Zhang, Y. Luo and Z. Hou, Macromolecules, 2008, 41, 1064-1066.

34 F. R. Mayo and F. M. Lewis, J. Am. Chem. Soc., 1944, 66, 1594-1601.

35 H.-H. Brintzinger, D. Ruchatz and G. Fink, Macromolecules, 2005, 38, 2056-2063.

36 F. Bonnet, H. E. Dyer, Y. El Kinani, C. Dietz, P. Roussel, M. Bria, M. Visseaux, P. Zinck and P. Mountford, Dalton Trans, 2015, 44, 12312-12325.

37 A. Valente, P. Zinck, A. Mortreux and M. Visseaux, J. Polym. Sci. Part Polym. Chem., 2011, 49, 1615-1620.

38 A. Valente, P. Zinck, A. Mortreux, M. Bria and M. Visseaux, J. Polym. Sci. Part Polym. Chem., 2011, 49, 3778-3782.

39 S. Loughmari, A. Hafid, A. Bouazza, A. El Bouadili, P. Zinck and M. Visseaux, J. Polym. Sci. Part Polym. Chem., 2012, 50, 2898-2905.

40 A. Ventura, T. Chenal, M. Bria, F. Bonnet, P. Zinck, Y. Ngono-Ravache, E. Balanzat and M. Visseaux, Eur. Polym. J., 2013, 49, 4130-4140.

41 S. Georges, A. O. Touré, M. Visseaux and P. Zinck, Macromolecules, 2014, 47, 45384547. 